\title{
MAPA GEOMORFOLÓGICO TÁTIL DO ESTADO DO RIO DE JANEIRO: UM RECURSO DIDÁTICO PARA DISCENTES COM DEFICIÊNCIA VISUAL
}

\author{
Vicente Passaglia. Pereira Cantanhede ${ }^{(a)}$, Raul Reis Amorim ${ }^{(b)}$ \\ (a) Departamento de Geografia, Instituto de Geociências, UNICAMP vicentecantanhede@ige.unicamp.br \\ (b) Departamento de Geografia, Instituto de Geociências, UNICAMP raul_reis@ige.unicamp.br
}

EIXO: GEOGRAFIA FÍSICA: CURRÍCULO, FORMAÇÃO E PRÁTICAS DE ENSINO

\begin{abstract}
Resumo
A Constituição Federal Brasileira de 1988 diz que todo brasileiro tem direito a estudar, além de ter igualdade de acesso escola (BRASIL, 1988). O direito universal ao acesso a educação ainda não é a realidade do país, tão pouco da qualidade da formação dos docentes para lidar com alunos especiais. Esse trabalho tem o objetivo auxiliar professores na elaboração e aplicação de materiais didáticos de baixo custo para deficientes visuais. Existem várias técnicas e metodologias de construção de materiais didáticos para o deficiente visual sentir, visualizar, estudar e entender o relevo. Aqui será exposto a construção e aplicação de um Mapa Tátil inspirado no Mapa Geomorfológico do Estado do Rio de Janeiro, na Escala 1: 500.000, elaborado pelo IBGE.
\end{abstract}

Palavra-Chave: Ensino de Geografia; Educação Especial, Deficiente Visual; Geomorfologia e Mata Tátil.

\section{Introdução}

Esse trabalho surgiu da necessidade de se fazer cumprir o direito constitucional de um aluno deficiente visual do curso de Geografia da Universidade Federal Fluminense - Instituto de Ciências da Sociedade e Desenvolvimento Regional - ESR, localizado na cidade de Campos dos Goytacazes - RJ.

O objetivo é apresentar uma das diversas formas de proposta de material adaptado para alunos cegos e aplicar de maneira correta. Com isso, buscou um mapa base, no qual foi o Mapa Geomorfológico do estado do Rio de Janeiro, na escala 1:500.000 publicado pela CPRM (2000). Os entendimentos conceituais da Geomorfologia estão estruturados em Florenzano (2008) e Christofoletti (1980). Já os conceitos da cartografia e dos mapas táteis são trabalhados na ideia de Almeida (2008) e Passini (2012).

Em nenhum momento desse trabalho a ideia é fomentar a ineficiência do professor, dizer por que não faz isso em vez daquilo ou querer ensinar alguma forma de lecionar. Esse trabalho também tem como proposta de alertar a importância de desenvolver políticas públicas educacionais para melhorar a qualidade do ensino na Educação Especial, a partir da inserção de uma melhor estrutura física da 
escola, da formação continuada dos docentes, do apoio aos familiares dos alunos com necessidades especiais, enfim, um conjunto de ações que de suporte a todos esses atores citados.

Tanto os mapas, quanto os conceitos aqui expostos, estão entrelaçados com os PCNs - Parâmetros Curriculares Nacionais da disciplina de Geografia (1998), o PCNs: Adaptações Curriculares (1998) e Currículo Mínimo de Geografia do Estado do Rio de Janeiro (2012).

\title{
2. Fundamentação teórica da construção do material.
}

O trabalho está estruturado na relação da Geomorfologia com a Cartografia e como o Ensino de Geografia pode elucidar esses conhecimentos para alunos deficientes visuais. Por tanto:

A cartografia é utilizada em Geomorfologia como meio de representação gráfica e espacial dos objetos e fenômenos estudados. O mapa, com respectiva legenda, expressa o resultado da análise e interpretação geomorfológica. Ele é, ao mesmo tempo, fonte de informação e um instrumento dela. É um instrumento de análise e síntese (FLORENZANO, 2008, p.105).

Nesse respectivo trabalho, também será abordado à importância da cartografia tátil na compreensão do relevo para o deficiente visual. Sendo assim, os mapas, quando elaborados corretamente e utilizando as técnicas adequadas, também são utes para os cegos que precisam se localizar no espaço.

Os meninos cegos de nascença aprendem a seguir um trajeto e até a resolver um problema de mudança de direção a partir de mapas táteis. Alguns cegos parecem ser capazes de usar o sol como um meio de achar o caminho. Verbalizando o trajeto é outro recurso (TUAN, 1983, p.85).

Sendo o leitor do mapa tátil, cego, com baixa visão, o vidente, ele vai precisar ser alfabetizado cartograficamente para entender e interpretar o mapa. Essa alfabetização está no campo da cartografia escolar, entrelaçado na Geografia e na cartografia. Para Passini (2012):

\begin{abstract}
Alfabetização cartográfica é uma metodologia que estuda os processos de construção de conhecimentos conceituais e procedimentais que desenvolvam habilidades para que o aluno possa fazer as leituras do mundo por meio das representações. É a inteligência espacial e estratégica que permite ao sujeito ler o espaço e pensar em sua Geografia. O sujeito que desenvolve essas habilidades para ser leitor eficiente de diferentes representações desenvolve o domínio do espaço (PASSINI, 2012, p.12).
\end{abstract}

Em nenhum momento a autora diz que o sujeito é deficiente visual, isso porque quando um bom mapa tátil é elaborado o aluno cego vai ter em seu entendimento, um mapa mental, compreender o que o mapa original exponha. No que se refere à cartografia tátil, Bittencourt, 2011 diz:

A cartografia escolar tátil é uma área da cartografia destinada ao ensino de todos os alunos, o que também inclui aqueles com deficiência visual. $\mathrm{O}$ atendimento às necessidades educacionais especiais dos alunos, pelas especificidades desses para o 


\section{OS DESAFIOS DA GEOGRAFIA FÍSICA NA FRONTEIRA DO CONHECIMENTO \\ Instituto de Geociências - Unicamp \\ Campinas - SP \\ 28 de Junho à 02 de Julho de 2017}

uso dos produtos cartográficos, exige a sistematização de diferentes formas de representação gráfica. (BITTENCOURT, 2011, p.85)

Para a construção de um mapa tátil exigem certa sensibilidade. Por exemplo, a utilização do material tátil, como: feijão, milho, arroz, macarrão, etc. que vai representar o relevo para o deficiente visual devem estar bem distintos um dos outros para melhor interpretação. O mapa tátil elaborado para esse trabalho dispõe, além dos materiais táteis, seis cores bem distintas uma das outras, para que alunos com baixa visão possam utilizar esse material. Ochaíta e Espinosa (2004) refletem sobre a importância do tato para os alunos cegos:

O tato é um dos principais sistemas sensórias que as crianças não-videntes utilizam para conhecer o mundo à sua volta. Suas características podem explicar boa parte das peculiaridades do desenvolvimento dessas crianças. O tato permite uma coleta de informação bastante precisa sobre os objetos próximos, mas é muito mais lento que a visão e, por isso, a exploração dos objetos grandes é fragmentária e sequencial (OCHAÍTA e ESPINOSA, 2004, p. 151).

Além dos elementos básicos de um mapa, título, legenda, norte e escala que são informações importantes para o aluno ler o mapa. Passini (2008) revela os primeiros passos para a compreensão do mapa:

Inicia-se uma leitura pela observação do título. Temos que saber qual o espaço representado, seus limites, suas informações. Depois, é preciso observar a legenda ou a decodificação propriamente dita, relacionando os significantes e o significado dos signos relacionados na legenda. É preciso também se fazer uma leitura dos significantes/significados espalhados no mapa e procurar refletir sobre aquela distribuição/organização. Observar também a escala gráfica ou numérica acusada no mapa para posterior cálculo das distâncias afim de se estabelecer comparações ou interpretações (PASSINI, 2008, p.17).

A cartografia da à possibilidade do aluno compreender os fenômenos naturas e sociais do mundo a partir do entendimento da leitura do mapa e mais importante que a leitura é ele perceber que faz parte desse todo:

A cartografia torna-se recurso fundamental para o ensino e a pesquisa. Ela possibilita ter em mãos representações dos diferentes recortes desse espaço e na escala que interessa para o ensino e pesquisa. Para a Geografia, além das informações e análises que se podem obter por meio dos textos em que se usa a linguagem verbal, escrita ou oral, torna-se necessário, também, que essas informações se apresentem espacializadas com localizações e extensões precisas e que possam ser feitas por meio da linguagem gráfica/cartográfica. É fundamental, sob o prisma metodológico, que se estabeleçam as relações entre os fenômenos, sejam eles naturais ou sociais, com suas espacialidades definidas. (...) O aluno deixou de ser visto como um mapeador mecânico para ser um mapeador consciente, de um leitor passivo para um leitor crítico dos mapas (PCN, 1998, p.76-77).

\section{Elaboração do material didático: Mapa Geomorfológico do Estado do Rio de Janeiro}


É importante salientar que todas as imagens desse trabalho, serão detalhadas, para caso algum deficiente visual queira estar a par do que se encontra no determinado conteúdo, tal como ocorre em filmes de áudio-descrição.

Foram feitas algumas modificações para adaptar o mapa aos deficientes visuais. Em vez de colocar no mapa tátil dezesseis objetos táteis, dos dezesseis tipos de relevo, criaram-se no lugar seis grupos, cada um representa um tipo de relevo característico do grupo. Essa generalização ajuda no entendimento do aluno deficiente visual ao fazer a leitura metal do mapa (BITTENCOURT, 2011).

Não existe um conceito exato que defina o que é um mapa tátil, Almeida (2008). Mas é importante respeitar as características de cada elemento por objetos táteis e que os mesmos encontram-se na legenda com sua descrição em braille.

A pessoa com deficiência visual depende do sentido tátil para formar conceitos espaciais, entender informações geográficas e criar internamente imagens do ambiente. Para isso, o processo de transformação dos dados geográficos em mapas e diagramas precisa ser adaptado a um produto final especifico, através de uma linguagem tátil, preferivelmente combina visual. (...) A cartografia tátil pode, certamente, melhorar o entendimento dos mapas e a prática cartográfica (ALMEIDA, 2008, p.127).

Almeida (2008) diz que os cartógrafos do mundo inteiro fazem perguntas para utilização dos mapas, no caso, “como? O quê? Para quem?" a última pergunta é importante para construir o mapa de acordo com o sujeito que queremos transmitir a informação.

Sendo assim, para construir o mapa tátil o primeiro passo foi escolher um mapa para se inspirar. Como foi dito anteriormente o mapa escolhido foi o Mapa Geomorfológico do Estado do Rio de Janeiro, logo foi colocado em cima do mapa uma folha de papel vegetal para fazer a delimitação territorial, do jeito que se encontra na Figura 1. Para deixar a folha bem esticada foi colocado alfinetes para segurar o mapa na folha vegetal. No mesmo, tem um lápis com $10 \mathrm{~cm}$ para servir como escola. 


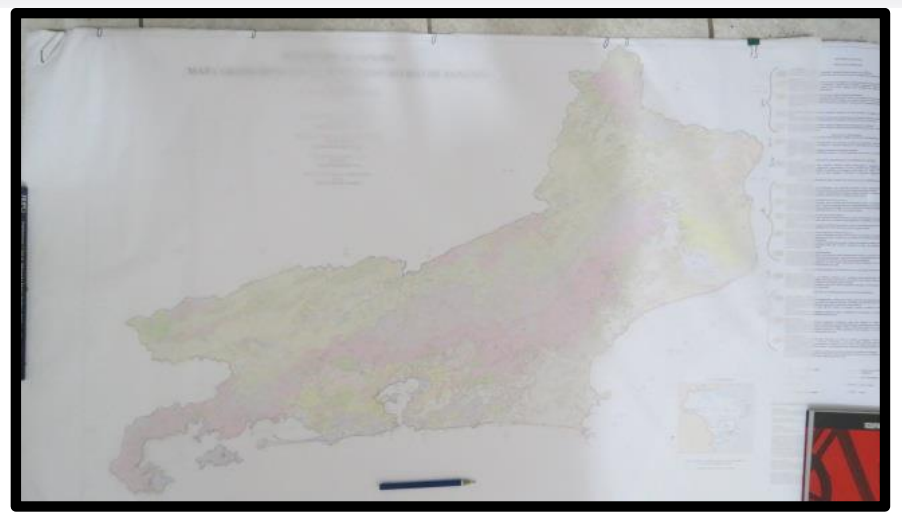

Figura 1 - Mapa Geomorfológico do Rio de Janeiro coberto com papel vegetal. Foto: Autor

Logo depois, com o lápis da Faber-Castell n², contorna-se a delimitação do território do Estado do Rio de Janeiro. O mesmo é feito nas compartimentações geomorfológicas. Na Figura 7 está localizada a Cidade de Paraty, na região sul do Estado referido.

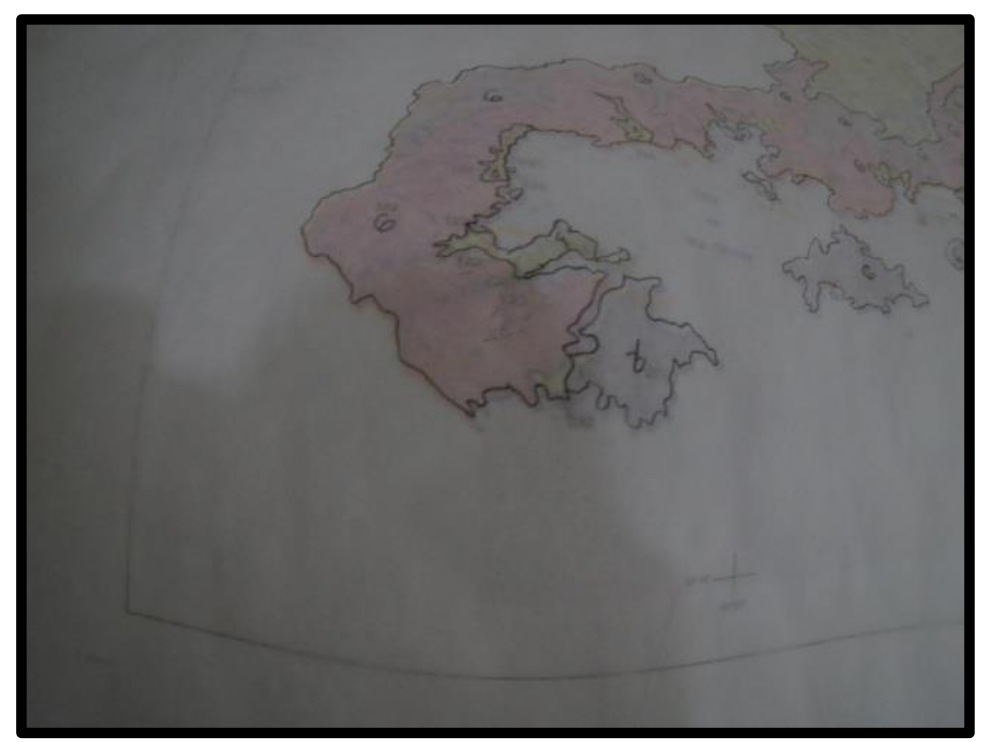

Figura 2- Delimitação dos compartimentos de relevo, a partir do agrupamento das sub-unidades - Região da Costa Verde. Foto: Autor

Por tanto, depois de fazer a delimitação do Estado, quem estiver elaborando o mapa precisa contornar cada compartimentação geomorfológica. Como está exposto na Figura 3. 


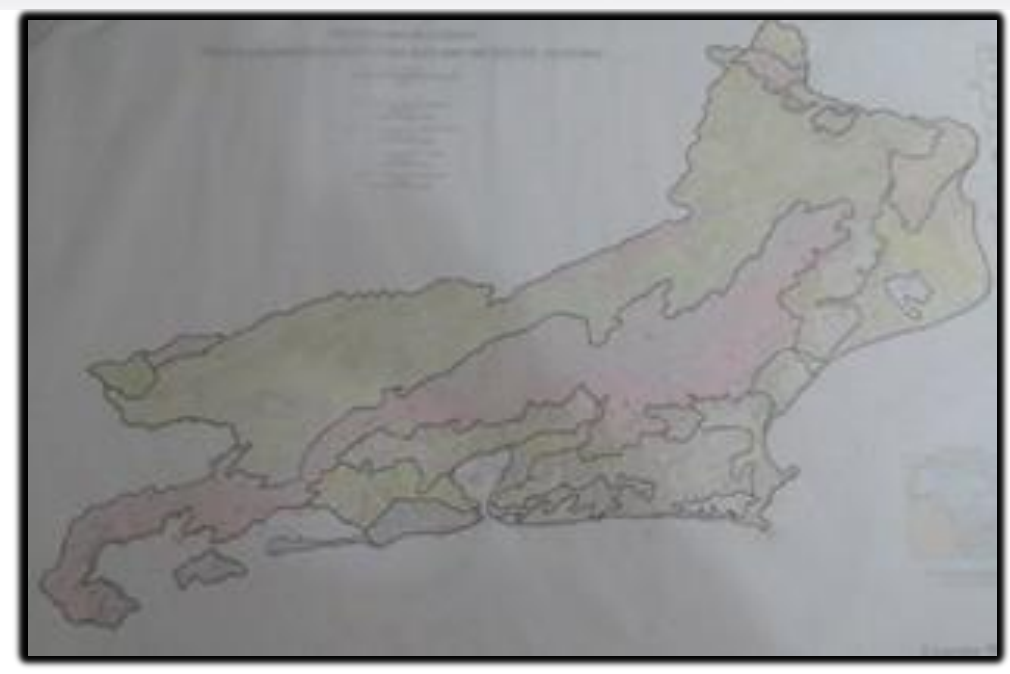

Figura 3 - Delimitação dos Compartimentos Geomorfológicos do Estado do Rio de Janeiro. Foto: Autor Ao elaborador do mapa, vai ao papel vegetal, onde se encontra-se a delimitação do do Estado do Rio de Janeiro e corta para colocar na cartolina. Atenção! Primeiro é a delimitação do Estado, depois as compartimentações geomorfologicas são cortadas, uma de cada vez, para assim ir tomando forma na cartolina.

Com a delimitação do Estado e das compartimentações geomorfologicas postas na cartolina, deve-se pintar cada uma com cores bem distintas umas das outras. Nesse trabalho foi feito com lápis de cor da Faber-Castell na cores: amarelo, vermelhor, laranja, roxo, verde escuro e rola claro. A Figura 4 com quatro imagens em sequencia mostrando a evolução na pitura no mapa tátil.

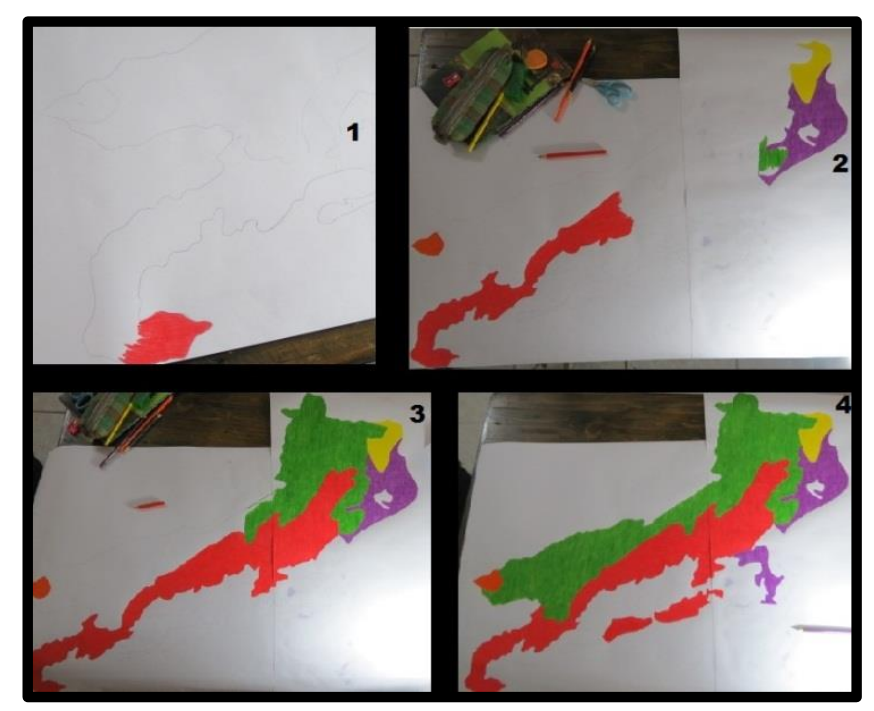

Figura 4 - Passo a passo para a Transposição dos compartimentos geomorfológicos do papel vegetal para a cartolina. Foto: Autor

Salienta-se que esse processo de pintura não deve ser feito com o papel oficio já colado no isopor, para não perfurar o mesmo. 


\section{OS DESAFIOS DA GEOGRAFIA FÍSICA NA FRONTEIRA DO CONHECIMENTO \\ Instituto de Geociências - Unicamp \\ Campinas - SP \\ 28 de Junho à 02 de Julho de 2017}

Concluindo essa etapa de pintura do mapa, deve-se encapar o mesmo, de preferência na cor branca com o material que achar mais adequado. Nesse caso, foi colocado quatro papeis sulfite tamanho ofício. Depois de recortar o mapa já colorido, pode-se enfim cola-lo no isopor já encapado.

$\mathrm{Na}$ Figura 5, o mapa está fixado na base. Para deixar em alto relevo as delimitações territoriais do Estado do Rio de Janeiro e as compartimentações geomorfológicas foram utilizadas uma cola especial em 3D, na cor preta. Mas também pode-se usar, dependendo do elaborador, barbante na cor que achar adequada.

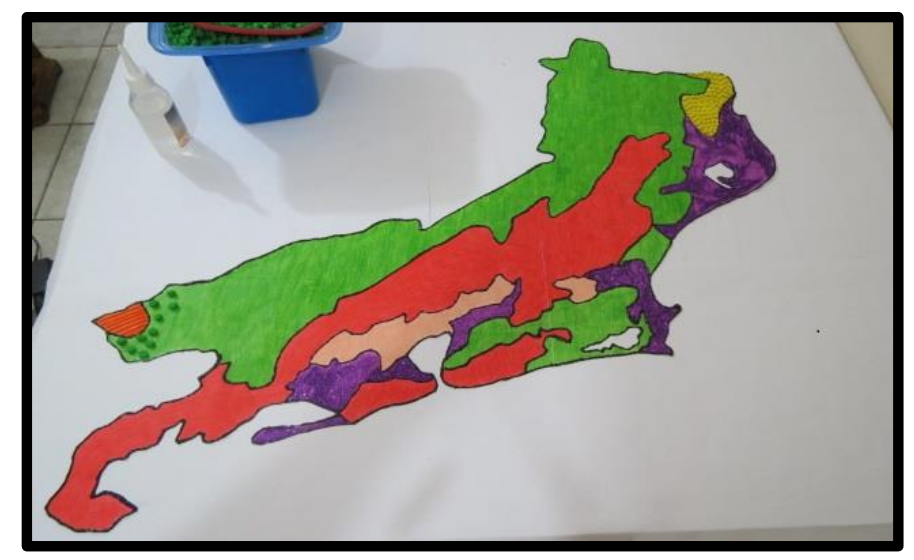

Figura 5 - Fase inicial de colagem das diferentes texturas do mapa tátil.

$\mathrm{Na}$ Figura 6 encontra-se uma evolução da figura anterior, em que, praticamente toda compartimentação dos Planaltos Resíduas cobertos por elementos táteis formados por milhos de pipoca na cor verde e toda área de Planície Costeira completo na cor roxa e com purpurina roxa como material tátil.

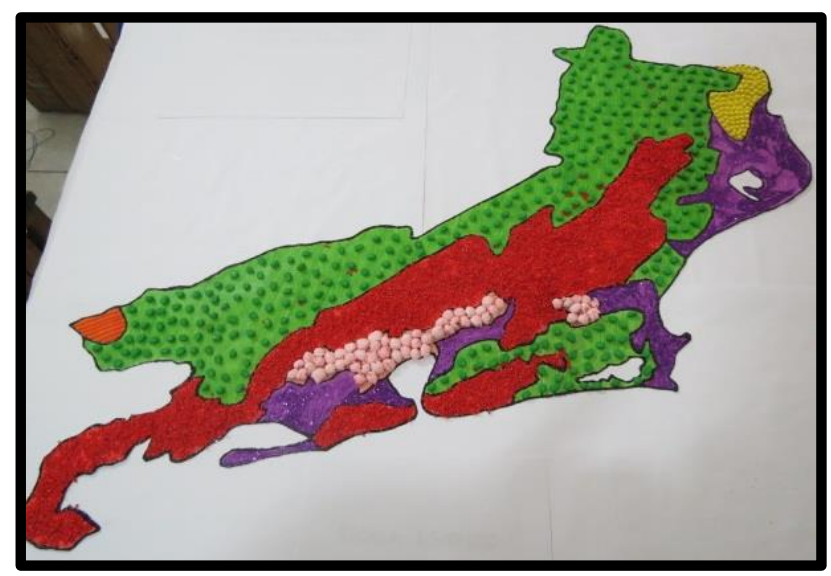

Figura 6 - Texturas inseridas no mapa tátil, diferenciadas por Compartimentação Geomorfológica 


\section{OS DESAFIOS DA GEOGRAFIA FÍSICA NA FRONTEIRA DO CONHECIMENTO \\ Instituto de Geociências - Unicamp \\ Campinas - SP \\ 28 de Junho à 02 de Julho de 2017}

Na sequência, mostra a Figura 7 mostra o mapa com todas as texturas inseridas, configurando assim, o mapa tátil e seus respectivos compartimentos geomorfológicos. Mas para realmente ser considerado um mapa, deve-se colocar os elementos básicos do mesmo, nos quais são: título, escala, legenda e o norte. As coordenadas geográficas podem ser marcadas no mapa, de lápis, e inserida sobre o mapa, quando o exercício for tratar de localização. Sugere-se construir as coordenadas geográficas com canudos plásticos. Fixar as coordenadas geográficas no mapa pode dificultar a leitura do mesmo pelos alunos. Como é um mapa tátil, todas informações textuais sobre ele são traduzidas para braille, dando a possibilidade do deficiente compreender os mapas. 


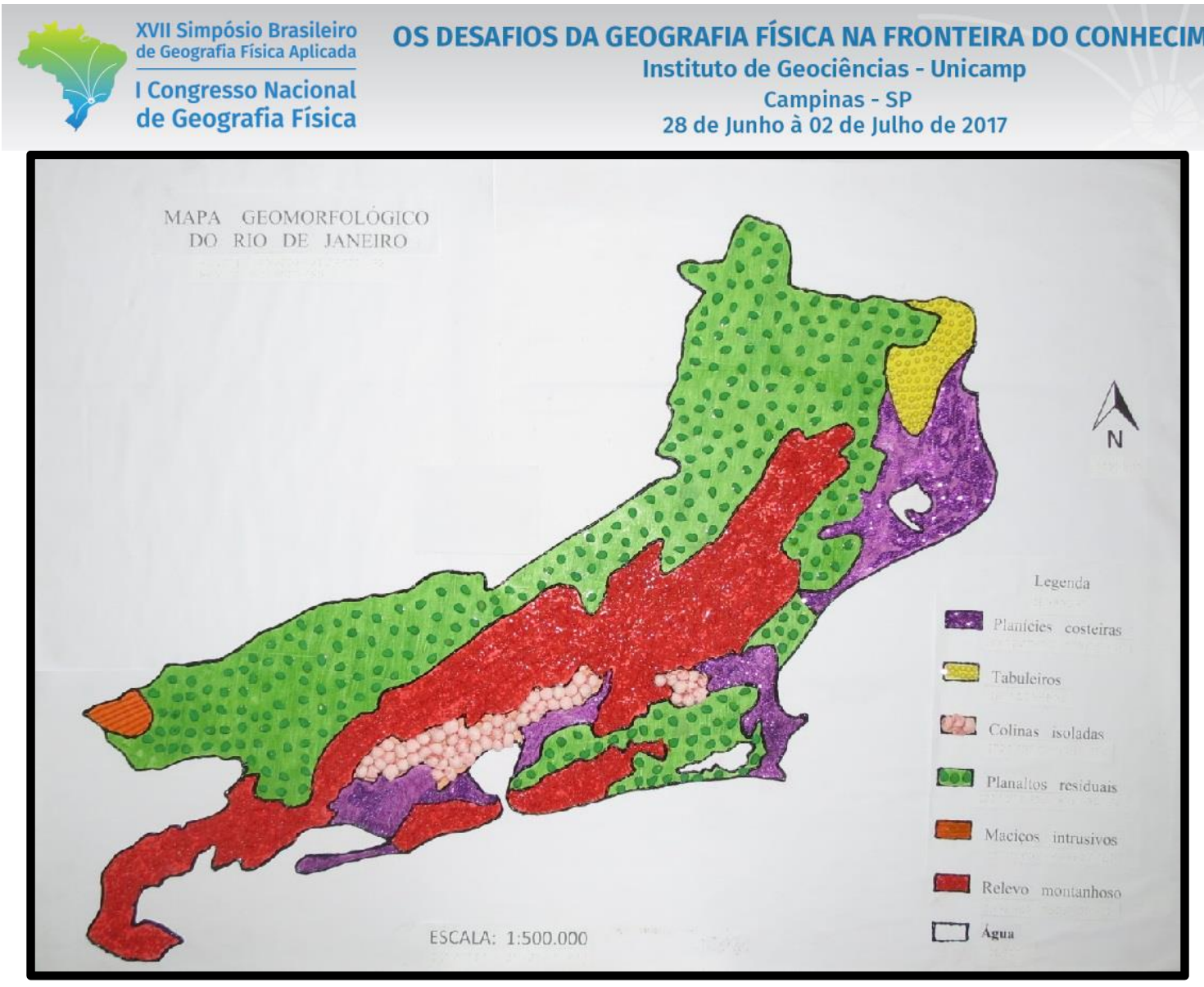

Figura 7 - Mapa Geomorfológico do Estado do Rio de Janeiro adaptado para Deficientes visuais e com baixa visão. Foto: Autor

Elaborou-se uma tabela na qual se encontra os itens utilizados, as cores e os compartimentos geomorfológicos.

Quadro 1 - Legenda para interpretação do mapa tátil Geomorfológico do Estado do Rio de Janeiro.

\begin{tabular}{|l|c|l|}
\hline \multicolumn{1}{|c|}{$\begin{array}{c}\text { Compartimentos } \\
\text { Geomorfológicos }\end{array}$} & Cor & \multicolumn{1}{|c|}{ Objetos Táteis } \\
\hline Planícies Costeiras & Roxo & Purpurina \\
\hline Tabuleiros & Amarelo & Alfinetes \\
\hline Colinas Isoladas & Rosa Claro & Papel Crepom \\
\hline Planaltos Residuais & Verde Escuro & Milho de Pipoca \\
\hline Relevo Montanhoso & Laranja & Macarrão \\
\hline Maciços Intrusivos & Vermelho & Arroz \\
& & \\
\hline
\end{tabular}




\title{
4. APLICAÇão DE ATIVIDADE PRÁTICA UTILIZANDO O MAPA TÁTIL
}

O mapa tátil foi avaliado por duas pessoas da área de educação especial. Umas delas foi a docente do Instituto São José para meninos cegos também Campos dos Goytacazes - RJ.

Mas o que interessava no momento era o entendimento o aluno. Sendo assim, chamamos alguns discentes. E foi perguntado a um discente se ele queria participar do entendimento do mapa. $\mathrm{O}$ mesmo ficou entusiasmado para participar e assim começamos.

É importante salientar que quando um deficiente visual busca compreender o mapa com a ponta dos dedos, ele demora mais tempo comparado aos videntes. Isso porque o cego tem uma leitura por parte e depois o entendimento do todo. Já o vidente obtém a dimensão geral do mapa logo da primeira vez. Dessa forma:

\begin{abstract}
Diferentemente da cartografia visual, é uma forma de comunicação sequencial, como um texto escrito. Ao ler um texto é necessário ler palavra por palavra para compreender as informações contidas em uma página, com a representação tátil ocorre o mesmo. Enquanto uma pessoa que enxerga tem uma visão global e imediata de um, mapa para depois prestar atenção nos detalhes, os usuários com deficiência visual descobrem a informação através de uma varredura sequencial para ao final obter uma "visão" global da informação. (BITTENCOURT, 2011, p.91 apud CARMO, 2009, p.47)
\end{abstract}

Na figura 8, o aluno B.M, vai começar a fazer a sua leitura do mapa. O primeiro passo é o mais importante, porque ele vai dar ao discente a dimensão geral dos limites territoriais do Estado do Rio de Janeiro. Para realizar tal exercício, o discente com o dedo indicador direito fixa o em um determinado ponto, nesse caso foi na Cidade de Arraial do Cabo - RJ, depois com o indicador esquerdo ele vai contornar todo o limite do mapa. Como mostra a figura 8 .

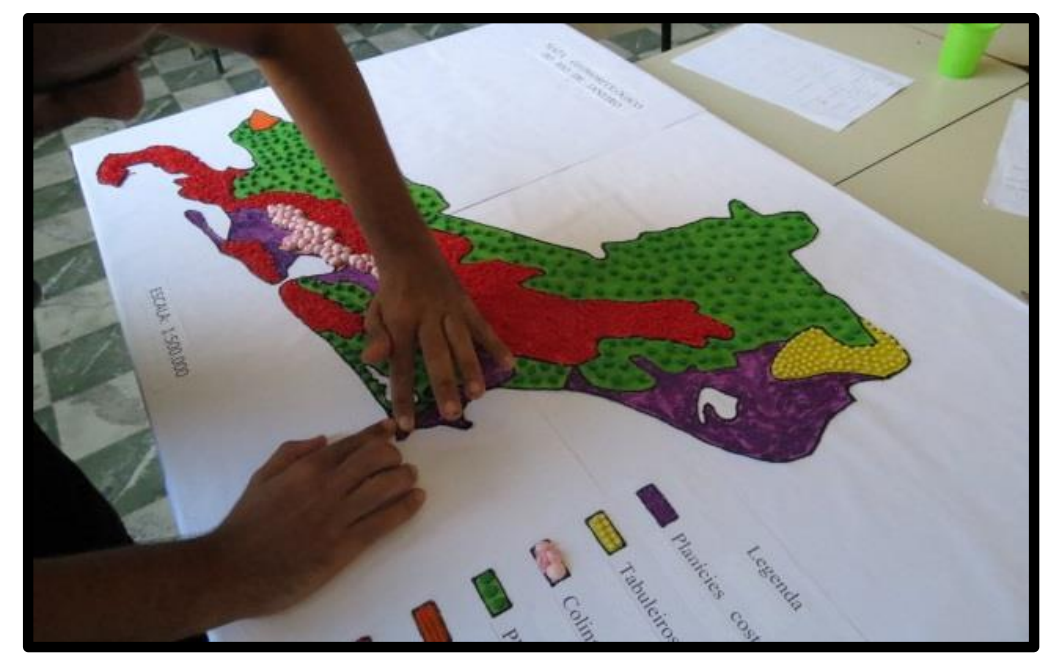

Figura 1 - Aplicação do Mapa Tátil com o Aluno do Instituto São José Operário Educandário para Cegos. 
Observado a figura 9, onde o aluno ainda continua com o indicador direito na Cidade de Arraial do Cabo - RJ, e com o indicador esquerdo no limite das cidades de Leopoldina (situada no Estado de Minas Gerais) e o município de Itaocara - RJ, no Noroeste do Fluminense. Quando terminar essa primeira etapa, ele terá um mapa mental em sua memória. Posteriormente esse processo vai se realizar em todas as compartimentações geomorfológicas.

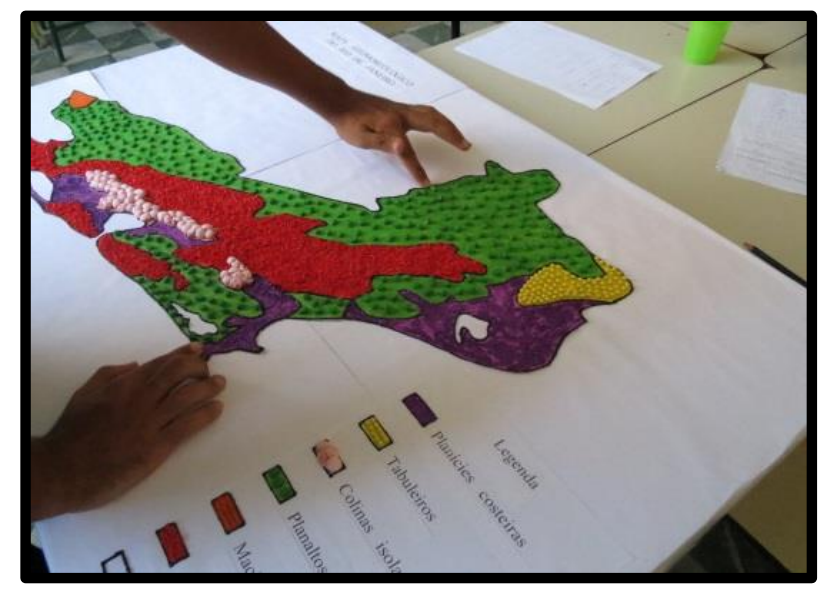

Figura 2 - Construção do Mapa metal do Aluno com Deficiência Visual

O mapa tátil bem produzido dá a possibilidade do aluno cego conhecer o espaço geográfico. Assim destaca-se a fala de Almeida (2008), o dizer que:

Os mapas têm o poder de criar imagens mentais dos lugares e fornecer uma noção do espeço que depende da visão. Além disso, para os usuários com deficiência visual, um mapa e uma bússola podem auxiliar na sua mobilidade, significando autonomia para se orientar nos percursos da vida cotidiana, em roteiros e até possíveis viagens. (ALMEIDA, 2008, p.140)

Dando sequência, o professor Raul da Escola Municipal Pequena Jornaleiro avaliou o mapa tátil. A avaliação dele era de extrema importância, já o que mesmo além de professo da sala de recursos também é cego, mas com uma diferença, ele sabe ler e escrever em braille, e o B.M ainda está aprendendo a ler e escrever esse código, o que dificultou na sua compreensão do mapa tátil.

Em seguida, o professor Raul avaliando o mapa tátil. Como ele já tem certa experiência foi feito um desafio com o mesmo para tentar de descobrir qual era o Estado exposto ali. Sem falar ainda o primeiro passo do docente foi fazer o mapa mental dos limites do território. Quando ele chegou na Baia de Guanabara o professor disse: “já sei, Rio de Janeiro!”. Depois o 
mesmo disse que cada Estado no Brasil tem algum tipo de característica no seu território, e isso facilita o entendimento.

Na Figura 11, o professor Raul analisa o conteúdo de uma compartimentação geomorfológica, depois o mesmo confere o nome na legenda, no caso se tratava dos planaltos residuais.

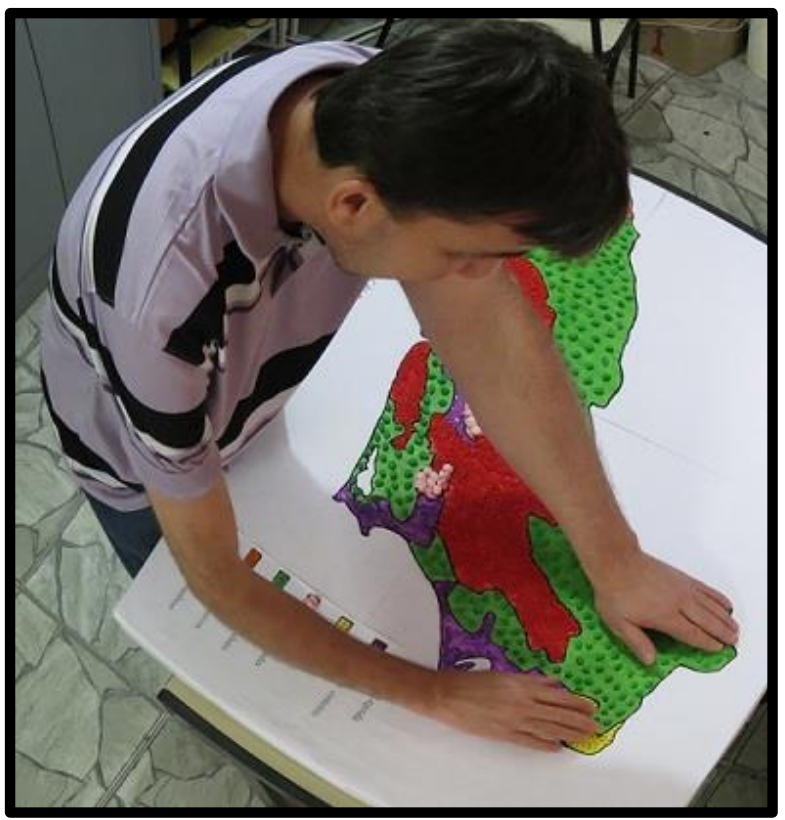

Figura 3 - Professor Raul tateando os Compartimentos Geomorfológicos.

Nas palavras do próprio professor: "Vicente, tá aprovadíssimo seu mapa. show de bola!". O mesmo destacou ainda a importância de trabalhos produzidos por alunos de universidade e aplicado aos alunos da escola básica. O mesmo disse: "a universidade precisa estar mais presente nas escolas".

Fica nesse trabalho uma reflexão sobre os desafios e as possibilidades dos professores frente a uma estrutura quase inexistente nas escolas. Mas independente do que vá se encontrar o docente precisa acreditar no seu aluno, porque se ela não acreditar o discente não vai ter motivação:

O profissional assume a convicção de que todos são capazes de aprender e de que o pressuposto de sua aprendizagem e sua interação com o mundo - sua ação sobre os objetos. Desse modo, o aluno precisa de ambientes estimuladores, não estereotipados. $\mathrm{O}$ conhecimento que o aluno vai adquirir depende da riqueza das experiências que lhe forem oferecidas. (RIBEIRO, 2003, p.49).

\section{Considerações finais}

No que se refere aos mapas táteis, foi uma verdadeira troca de ideias e saberes entre o aluno da pesquisa e os professores citados na mesma. Sobre o discente B.M, o mesmo se encontra em 
processo de alfabetização em braille, por conta disso dificultou um pouco esse processo de entendimento do mapa. Sabia-se que seria muito complicado explicar para o aluno as compartimentações geomorfológicas, mas de qualquer forma fui importante, tendo em vista que foi a primeira vez que o aluno citado manuseou mapa tátil daquelas proporções.

O principal objetivo foi alcançado, que era dar ao discente uma noção geral dos limites territoriais do Estado do Rio de Janeiro e dos relevos, localizar-se no mapa e treinar o tato nos objetos tátil. Infelizmente não foi possível trabalhar mais com outros alunos deficientes visuais, já que mesmos são novos e tímidos, ficou um certo ar de desconfiança. Mas o importante é que o primeiro passo foi dado e agora a Universidade Federal Fluminense - Campos dos Goytacazes criou laços com essas instituições.

Ficou evidente, que o professor mais bem preparado pode lecionar com os alunos deficientes visuais. Mas na hora de trabalhar com os alunos alguns aspectos de abordagem podem ajudar no seu desenvolvimento, tais como: uma sala de recursos com professor capacitado para lidar com discentes especiais, matérias adaptados e na hora de aplicar ter um posicionamento correto para ajudar no seu desenvolvimento de ensino-aprendizagem.

Não importa se a escola tem todos os recursos possíveis se o próprio professor não acredita em seu aluno. $\mathrm{O}$ docente precisa entender que aquele momento é mais um desafio na sua careira e precisa buscar soluções para adaptar sua a aula aos discentes deficientes visuais, criando um ambiente inclusivo.

\section{REFERÊNCIAS}

ALMEIDA, R. D. de; PASSINI, E. O espaço Geográfico: ensino e representação. 15. ed.,2 $2^{a}$ reimpressão São Paulo: Contexto, 2008.

ASCENSÃO, V. de O, VALADÃO R. C.. "Abordagem do conteúdo "relevo" na Educação Básica." CAVALCANTI, LS Temas da Geografia na escola básica. Campinas, SP: Papirus (2013).

BITTENCOURT, A. A LINGUAGEMCARTOGRÁFIA E A MEDIAÇÃO DA APRENDIZAGEM PELO PROCESSO DE DESENVOLVIMENTO DE MATETRIAIS DIDÁTICOS TÁTEIS: Experiências com professores em formação continuada. Dissertação (Mestrado) - Departamento de Geografia FFLCH - Universidade de São Paulo. São Paulo : 2011

BRASIL. Secretaria de Educação Fundamental. Parâmetros curriculares nacionais: Adaptações Curriculares / Secretaria de Educação Especial - Brasília: MEC/ SEF / SEESP, 1998. Disponível em: < http://www.conteudoescola.com.br/pcn-esp.pdf $>$. Acesso em: 27/ setembro/2014.

CHRISTOFOLETTI, Antonio.Geomorfologia. No. 551.4 CHRI. 1980.

FLORENZANO, T. G. (Org) GEOMORFOLOGIA: conceitos e tecnologias atuais. São Paulo : Oficina de Textos, 2008.

PASSINI, E. Y. ALFABETIZAÇÃO CARTOGRAFICA e a APRENDIZAGEM de GEOGRAFIA. São Paulo : Cortez, 2012.

TUAN, Yi-Fu. Espaço e lugar: a perspectiva da experiência. São Paulo: Difel, 1983. 